\title{
Methylprednisolone blocks interleukin 1 beta induced calcitonin gene related peptide release in trigeminal ganglia cells
}

\author{
Lars Neeb $^{1 *}$, Peter Hellen ${ }^{2}$, Jan Hoffmann ${ }^{1,3}$, Ulrich Dirnagl ${ }^{1}$ and Uwe Reuter ${ }^{1}$
}

\begin{abstract}
Background: Methylprednisolone (MPD) is a rapid acting highly effective cluster headache preventive and also suppresses the recurrence of migraine attacks. Previously, we could demonstrate that elevated CGRP plasma levels in a cluster headache bout are normalized after a course of high dose corticosteroids. Here we assess whether MPD suppresses interleukin-1 $\beta$ (IL-1 $\beta$ )- and prostaglandin $E_{2}\left(P_{G} E_{2}\right)$-induced CGRP release in a cell culture model of trigeminal ganglia cells, which could account for the preventive effect in migraine and cluster headache. Metoprolol(MTP), a migraine preventive with a slow onset of action, was used for comparison.

Methods: Primary cultures of rat trigeminal ganglia were stimulated for $24 \mathrm{~h}$ with $10 \mathrm{ng} / \mathrm{ml} \mathrm{IL-1 \beta}$ or for $4 \mathrm{~h}$ with $10 \mu \mathrm{M} \mathrm{PGE}$ following the exposure to 10 or $100 \mu \mathrm{M}$ MPD or $100 \mathrm{nM}$ or $10 \mu \mathrm{M} \mathrm{MTP}$ for $45 \mathrm{~min}$ or $24 \mathrm{~h}$. CGRP was determined by using a commercial enzyme immunoassay.

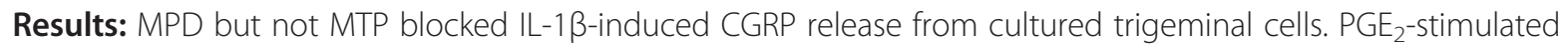
CGRP release from trigeminal ganglia cell culture was not affected by pre-stimulation whether with MPD or MTP.

Conclusion: MPD but not MTP suppresses cytokine (IL-1 $\beta$ )-induced CGRP release from trigeminal ganglia cells. We propose that blockade of cytokine mediated trigeminal activation may represent a potential mechanism of action that mediates the preventive effect of MTP on cluster headache and recurrent migraine attacks.
\end{abstract}

Keywords: Cluster headache, Migraine, Trigeminal ganglia cells, Calcitonin gene related peptide, Methylprednisolone, Metoprolol, Interleukin-1 $\beta$, Prostaglandin $E_{2}$

\section{Background}

The trigeminal system and the neuropeptide calcitonin gene-related peptide (CGRP) are key players in migraine and cluster headache pathophysiology. Activation of perivascular trigeminal nerves within the meninges causes the release of CGRP [1, 2]. CGRP plasma levels were elevated during migraine and cluster headache attacks and effective attack treatment led to the normalization of CGRP levels $[3,4]$. The release of CGRP contributes to vasodilatation, neurogenic inflammation, transmission of pain signals and central sensitization [5]. These mechanisms seem to be of significance in migraine pathophysiology and might also be involved in cluster headache pathophysiology.

\footnotetext{
* Correspondence: lars.neeb@charite.de

${ }^{1}$ Department of Neurology and Experimental Neurology, Charité Universitätsmedizin Berlin, Charitéplatz 1, 10117 Berlin, Germany Full list of author information is available at the end of the article
}

CGRP plasma levels may also serve as biomarkers for primary headaches. Patients with episodic and chronic migraine demonstrate elevated CGRP plasma levels between attacks [6]. Recently, we could demonstrate that CGRP plasma levels are elevated interictally in episodic cluster headache patients in the bout and that these levels are reduced after short term prophylaxis with corticosteroids [7]. We hypothesized that elevated CGRP plasma levels in a cluster bout might represent a hyperactive state of the trigeminal nervous system. Suppression of trigeminal hyperactivity could be a consequence of corticosteroid therapy, which in turn leads to the suppression of cluster headache attacks. However, our study could not exclude that altered CGRP levels were rather a consequence than the cause of the reduced attack frequency.

Previously, we observed in cultured trigeminal ganglia cells that interleukin $1 \beta(\mathrm{IL}-1 \beta)$ and prostaglandin $E_{2}$
Springer

C 2016 Neeb et al. Open Access This article is distributed under the terms of the Creative Commons Attribution 4.0 International License (http://creativecommons.org/licenses/by/4.0/), which permits unrestricted use, distribution, and reproduction in any medium, provided you give appropriate credit to the original author(s) and the source, provide a link to the Creative Commons license, and indicate if changes were made. 
$\left(\mathrm{PGE}_{2}\right)$ induce CGRP release in a cyclooxygenase-2 dependent pathway [8]. Cytokines and especially IL-1 $\beta$ have been linked to migraine $[9,10]$ and cluster headache [11] and an involvement of pro-inflammatory cytokines in the pathophysiology of primary headaches is probable.

To determine whether corticosteroids may influence trigeminal activation directly, we studied the effects of corticosteroids on CGRP release in this trigeminal ganglia cell model using IL-1 $\beta$ and $\mathrm{PGE}_{2}$ for stimulation. In addition to short-term cluster headache prophylaxis methylprednisolone (MPD) is also used to abort a migrainous state or to prevent the recurrence of migraine attacks [12]. Therefore, we compared the effects of MPD, a drug with rapid onset of action, with the slowly acting migraine preventive metoprolol (MTP) on CGRP release in this model.

\section{Methods}

\section{Animals}

We used 3-day-old male and female Sprague Dawley rats (Charles River, Sulzheim, Germany). All animals were kept under standard laboratory housing conditions with a $12 \mathrm{~h}$ light-dark cycle and with an adult female Sprague Dawley rat (Charles River, Sulzheim, Germany) with free access to food and water. For cell culture procedures newborn animals were anaesthetized with an isoflurane vaporizer $(4 \%)$ and decapitated. All animal work was carried out in accordance with the European Communities Council Directive of 24 November 1986 (86/609/EEC) regarding the care and use of animals for experimental procedures. The sacrifice of the rats and extraction of their brains was approved by and reported to the Landesamt für Gesundheit und Soziales Berlin (LaGeSo; T0322/96).

\section{Cell culture}

Trigeminal ganglia cell culture was established as previously described by our group [8]. In brief, trigeminal ganglia were dissected from 3 day old male and female Sprague Dawley rats (Charles River, Sulzheim, Germany). The cells were incubated for $90 \mathrm{~min}$ at $37^{\circ} \mathrm{C}$ in $10 \mathrm{ml}$ dissociation medium (modified eagles medium; Biochrom, Berlin, Germany; with $10 \%$ bovine serum, 10 mM HEPES, $44 \mathrm{mM}$ glucose, $100 \mathrm{U}$ penicillin + streptomycin, $2 \mathrm{mM}$ glutamine, $100 \mathrm{IE}$ insulin/l) containing collagenase/dispase (final concentration $100 \mu \mathrm{g} / \mathrm{ml}$ ) (Boehringer Mannheim, Germany), rinsed twice with phosphate buffered saline (PBS) $0.1 \mathrm{M}$ and again incubated with trypsin/EDTA $(0.05 \% / 0.02 \% \mathrm{w} / \mathrm{v}$ in PBS) for $30 \mathrm{~min}$ for dissociation. Subsequently, cells were rinsed twice with PBS and once with dissociation medium, dissociated by Pasteur pipette and pelleted by centrifugation at $2100 \mathrm{xg}$ for $2 \mathrm{~min}$ at $21^{\circ} \mathrm{C}$. After suspension in starter medium (Invitrogen, Karlsruhe, Germany) plus $1 \%$ penicillin/streptomycin, 0,25 \% L- glutamine, $2 \%$ B27-supplement, 0,1 \% $25 \mathrm{mM}$ glutamate, $2.5 \mathrm{mM}$ calcium chloride and $100 \mathrm{ng} / \mathrm{ml}$ nerve growth factor- $\beta$, cells were plated in 24 well plates and filled to $500 \mu \mathrm{l}$ with starter medium at a density of $0.5 \times 10^{-6}$ cells/ $\mathrm{cm}^{2}$ (equates approximately 2 ganglia/well). Wells were pretreated by incubation with poly-l-lysin $(5 \% \mathrm{w} / \mathrm{v}$ in PBS) for 90 min at $4{ }^{\circ} \mathrm{C}$, then rinsed with PBS, followed by incubation with coating medium (dissociation medium with $1 \%$ w/v collagen G) for $90 \mathrm{~min}$ at $37{ }^{\circ} \mathrm{C}$ in the incubator. After that, the wells were rinsed twice with PBS and filled with starter medium in which cells were seeded. Cytosine arabinoside (final concentration $10 \mu \mathrm{M}$; Sigma Aldrich, Munich, Germany) was added at day 1 and day 3 to minimize growth of non-neuronal cells. Cultures were kept at $37{ }^{\circ} \mathrm{C}$ and $5 \% \mathrm{CO}_{2}$ and fed with neurobasal medium + B27 medium every second day by replacing $50 \%$ of the medium. Condition of cultures was assessed by light microscopy. Stimulation experiments were performed on day 6 .

\section{CGRP determination by enzyme immunoassay}

After 6 days in culture the medium was gently removed and replaced with fresh medium without nerve growth factor to exclude effects of nerve growth factor on protein release. $1 \mathrm{~h}$ later cells were stimulated for $24 \mathrm{~h}$ with IL-1 $\beta(10 \mathrm{ng} / \mathrm{ml}), 4 \mathrm{~h}$ with $\mathrm{PGE}_{2}(10 \mu \mathrm{M})$ or equal volume of vehicle (PBS 0.1 M). For inhibition studies cells were pre-incubated with MPD $(10 \mu \mathrm{M}$ or $100 \mu \mathrm{M})$, MTP $(100 \mathrm{nM}$ or $10 \mu \mathrm{M})$ or PBS $45 \mathrm{~min}$ or $24 \mathrm{~h}$ prior to simulation with vehicle (PBS), IL-1 $\beta$ or $\mathrm{PGE}_{2}$. Immediately before the stimuli $50 \mu$ l supernatant of each well were removed to assess baseline CGRP levels. At the end of the stimulation supernatants of two dishes were pooled and used for CGRP determination with a specific CGRP enzyme immunoassay (SPIbio, Montigny le Bretonneux, France) as recommended by the manufacturer. For each experiment, one set of wells was treated with $60 \mathrm{mM} \mathrm{KCl}$ to determine the responsiveness of the cultures to an established depolarizing stimulus [13]. Cultures that exhibited a response less than 2-fold on CGRP release after the depolarizing stimulus were not analyzed. CGRP release was determined in $\mathrm{pg} / \mathrm{ml}$ as absolute increase over baseline values in the corresponding two wells (CGRP levels after stimulation - baseline CGRP levels before stimulation). All samples were measured in duplicates. Each experimental condition was repeated in at least seven independent experiments.

\section{Statistical analysis}

Due to small sample size nonparametric statistics were used. Differences of CGRP values between groups were analysed with the Kruskal-Wallis $\mathrm{H}$ test. If this test showed statistical significance pairwise comparison was performed using the Mann-Whitney U test. Resulting 
$p$-values were adjusted for multiple comparisons using the Bonferroni-Holm method. Corrected $p<0.05$ was considered statistically significant. All statistical tests were performed with the SPSS 20 statistical software (SPSS, Chicago, IL, USA). Data are shown as mean \pm standard error of the mean (SEM).

\section{Results}

In a first step we investigated the effect of MPD on basal and stimulated CGRP release in cultures of rat trigeminal ganglia cells. Cultures were pretreated with vehicle (PBS) or MPD (10 or $100 \mu \mathrm{M})$ for 45 min followed by stimulation with PBS or IL- $1 \beta(10 \mathrm{ng} / \mathrm{ml})$ for $24 \mathrm{~h}$.

A Kruskal-Wallis $\mathrm{H}$ test showed that there was a statistically significant difference in CGRP levels between the different stimulations $\left(X^{2}(3)=10.270, p=0.016\right)$. Pairwise comparison using the Mann-Whitney U test with correction for multiple comparison (BonferroniHolm method) revealed that stimulation of trigeminal ganglia cells with IL-1 $\beta$ led to a significantly increased CGRP release compared to control (PBS) (IL-1ß: $638 \pm 189$ SEM pg/ml vs. PBS: $295 \pm 48$ SEM $\mathrm{pg} / \mathrm{ml} ; n=9 ; p=0.031$ ). Administration of $10 \mu \mathrm{M}$ or $100 \mu \mathrm{M}$ MPD into the culture (45 min before stimulation with IL-1 $\beta$ ) led to a statistical significant suppression of IL- $1 \beta$-stimulated CGRP release $(310 \pm 47 \mathrm{SEM} \mathrm{pg} / \mathrm{ml}$; $p=0.022(10 \mu \mathrm{M})$ and $264 \pm 74$ SEM $\mathrm{pg} / \mathrm{ml} ; p=0.012$ $(100 \mu \mathrm{M}) ; n=9)$. In contrast, pretreatment of cultures with MPD for 45 min itself without adding IL-1 $\beta$ did not significantly change the amount of CGRP release in controls (PBS exposure solely) (Fig. 1).

Subsequently we tested if $\mathrm{PGE}_{2}$-induced CGRP release is also altered by pre-stimulation with MPD. There was a statistically significant difference in the CGRP levels between different stimulations as determined by a Kruskal-Wallis H test $\left(X^{2}(3)=10.318, p=0.016\right)$ Stimulation of cultured trigeminal ganglia cells with $\mathrm{PGE}_{2}$ $(10 \mu \mathrm{M})$ for $4 \mathrm{~h}$ led to significantly increased CGRP levels in the supernatant compared to PBS (324 \pm 93 vs. $33 \pm 7 \mathrm{pg} / \mathrm{ml} \mathrm{SEM} ; n=8, p<0.0001)$. However, the administration of MPD $10 \mu \mathrm{M}(n=8)$ or $100 \mu \mathrm{M}(n=7)$ to trigeminal ganglia cells $45 \mathrm{~min}$ prior to $\mathrm{PGE}_{2}$ stimulation did not alter CGRP release compared to pre-stimulation with vehicle (PBS) $(p>0.05)$. The extension of MPD exposure to $24 \mathrm{~h}$ did neither affect $\mathrm{PGE}_{2}$-induced CGRP release $(n=8)$ (Fig. 2).

In a second step we assessed whether the exposure to MTP had any effect on IL-1 $\beta$ - or PGE $_{2}$-induced CGRP release. In contrast to MPD, MTP did not change significantly the amount of stimulus-induced CGRP release in this model. There was a trend towards lower CGRP levels in cultures pretreated with MTP 45 min prior to $\mathrm{PGE}_{2}$ exposure. However, the results did not reach statistical significance $(p=0.14 ; n=9)$, (Figs. 3 and 4$)$. In
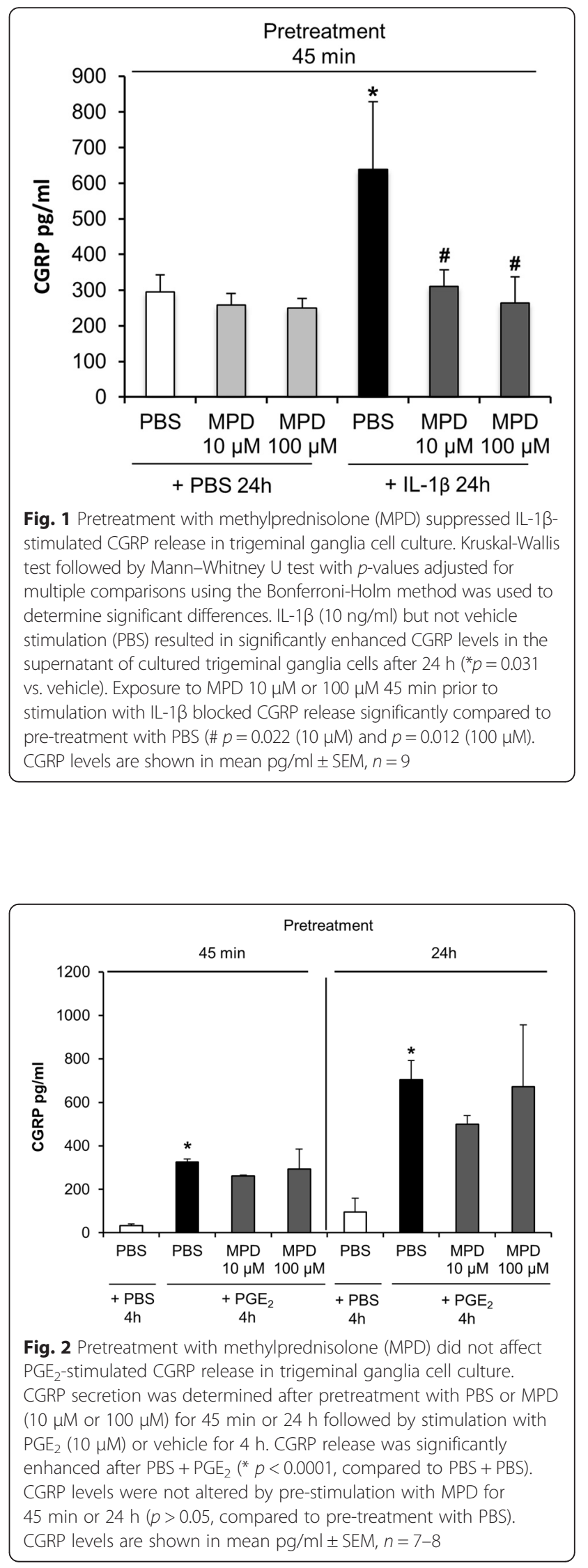


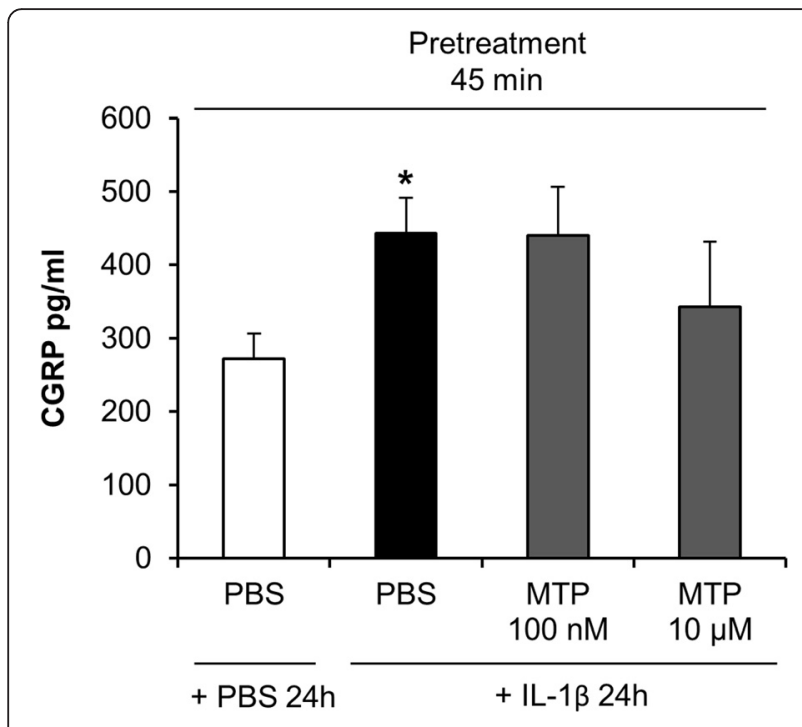

Fig. 3 Exposure to metoprolol (MTP) did not affect IL-1 $\beta$-stimulated CGRP release in trigeminal ganglia cell culture. CGRP secretion was determined $45 \mathrm{~min}$ after pretreatment with MTP (100 nM and $10 \mu \mathrm{M})$ respectively PBS followed by a $24 \mathrm{~h}$ exposure to PBS or IL-1 1 (10 ng/ $\mathrm{ml})$. IL-1 $\beta$ stimulation for $24 \mathrm{~h}$ led to a significant CGRP release compared to vehicle stimulation ( ${ }^{*} p=0.042$ ) which was not altered by pre-treatment with MTP (100 nM or $10 \mu \mathrm{M})(p>0.05$, compared to pre-treatment with PBS). CGRP levels are shown in mean $\mathrm{pg} / \mathrm{ml} \pm \mathrm{SEM}, n=9$

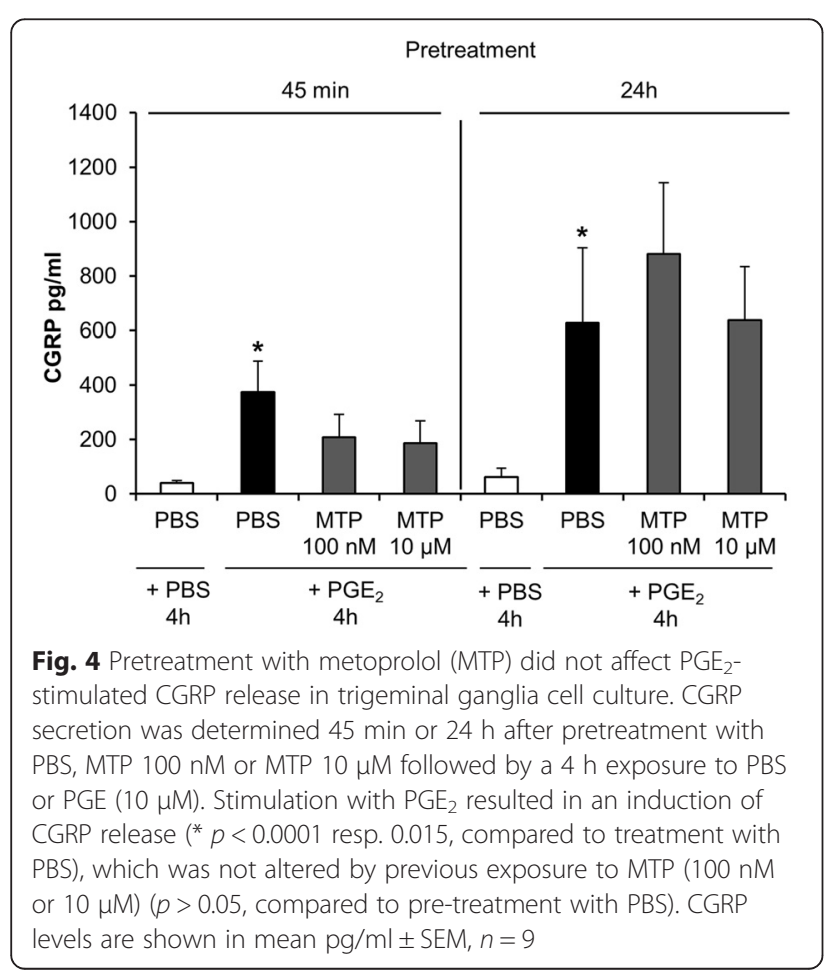

preliminary experiments $(n=4)$ higher concentrations of MTP $(100 \mu \mathrm{M})$ did neither alter CGRP release in this model.

\section{Discussion}

In this study MPD blocked IL-1 $\beta$-induced CGRP secretion in a trigeminal ganglion cell culture model. MPD had no effect on $\mathrm{PGE}_{2}$-stimulated CGRP release. Vehicle treated CGRP release in cultured trigeminal ganglia cells was not affected by MPD. The migraine preventive MTP

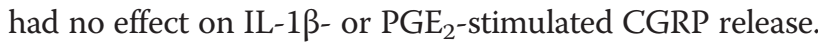
In contrast, previous studies in a similar cell culture model showed that the migraine preventives topiramate and botulinum toxin type A blocked CGRP release in cultured trigeminal ganglia cells when stimulated with $\mathrm{KCl}$, capsaicin, protons or nitric oxide $[14,15]$.

Concentrations and time points for stimulation with IL-1 $\beta$ or $\mathrm{PGE}_{2}$ were determined by previous results in this model with maximum CGRP release at these values [8]. Doses for MPD (10 or $100 \mu \mathrm{M})$ and MTP (100 nM and $10 \mu \mathrm{M})$ used in this experimental study were derived from human data on serum concentrations after applying therapeutically beneficial doses of the drugs. Intake of $80 \mathrm{mg}$ oral methylprednisolone leads to a serum concentration of $7 \mu \mathrm{M}$ [16]. Intravenous administration of $1000 \mathrm{mg}$ methylprednisolone results in serum concentrations between 16 and $77 \mu \mathrm{M}$ [17]. Mean serum concentrations of metoprolol after oral application of $100 \mathrm{mg}$ were stated with $136 \mathrm{nM}$ [18]. To assess a maximal effect we chose the higher metoprolol dose equal to the effective dose of methylprednisolone $(10 \mu \mathrm{M})$.

For pre-stimulation with MTP and MPD we chose $45 \mathrm{~min}$ and $24 \mathrm{~h}$ before the exposure to $\mathrm{PGE}_{2}(4 \mathrm{~h})$ to assess the acute effect of stimuli as well as effects that may be mediated through longer acting mechanisms ( e.g. gene expression). Due to the long exposure to IL-1 $\beta$ ( $24 \mathrm{~h}$ ) prestimulation was restricted to $45 \mathrm{~min}$ in these experiments.

Primary trigeminal afferents are a major source of CGRP release into the extracerebral circulation [19]. Activation of trigeminal ganglia afferents and subsequent release of CGRP is thought to play a prominent role in the pathophysiology of migraine [20] and cluster headache $[21,22]$ pathophysiology. The pro-inflammatory cytokine IL-1 $\beta$ and other cytokines are elevated in migraine $[9,10]$ and cluster headache patients $[11,23,24]$. The cytokines IL-1 $\beta$ and tumor necrosis factor alpha induce CGRP release in cultured trigeminal ganglia cells $[8,25]$. The involvement of immunological mechanisms in primary headaches is possible but the role of cytokines in headache pathophysiology remains incompletely understood.

Cytokines are proteins that are released by glial cells in proximity to peripheral and central neurons. They are involved in pro-inflammatory signaling pathways and 
represent key elements in the induction and maintenance of pain [26-30]. Increased cytokine expression and pro-inflammatory protein synthesis are both pathophysiological components for the development and maintenance of peripheral and central sensitization. Both mechanisms are important in the pathophysiology of migraine [26, 31, 32]. CGRP itself differentially regulates cytokine secretion from cultured trigeminal ganglion glia cells. In CGRP treated cultures secreted levels of some cytokines (e.g. IL- $\beta$ ) increased while others such as tumor necrosis factor alpha decreased. These results point to a paracrine trigeminal activation due to CGRP release from trigeminal ganglia neurons and glial cytokine secretion that may lead to an inflammatory loop, which could account for sustained sensitization of second-order trigeminal neurons [33]. Chronically sensitized central nociceptive neurons are supposed to contribute to the development of chronic migraine and its resistance to treatment [34].

In contrast to IL- $1 \beta$-induced CGRP release, $\mathrm{PGE}_{2}$-induced CGRP release was not affected by prior exposure to MPD. Previously, we demonstrated that IL-1 $\beta$ induced CGRP release in trigeminal ganglia cells is dependent on COX-2 induction [8]. Methylprednisolone prevents $\mathrm{PGE}_{2}$ formation by suppression of $\mathrm{COX}-2$ activity [35]. If inhibition of CGRP release by methylprednisolone is mediated through the prevention of $\mathrm{PGE}_{2}$ formation, it is feasible that direct induction of CGRP release by $\mathrm{PGE}_{2}$ cannot be blocked by methylprednisolone. In a recent clinical study, we demonstrated the effect of MPD on CGRP release in episodic cluster headache patients in an active bout. A three day pulse therapy with $1000 \mathrm{mg}$ MPD per day led to the normalization of interictally elevated CGRP plasma levels in parallel to the suppression of headache attacks [7]. We extend this observation with our experimental findings in a cell culture of trigeminal ganglia cells. This data support the hypotheses that corticosteroids might exert their preventive action in migraine and cluster headache by the inhibition of trigeminal activation, which is necessary for the initiation of a headache attack. Blockade of trigeminal neurotransmitter secretion could account for prevention of central sensitization and triggering of headache attacks.

Metoprolol, a migraine preventive with slow onset of action had no effect in this experimental model. MTP seems to mediate its prophylactic effect through an alternative mode of action on possible noninflammatory mechanisms and not on a cellular level in the trigeminal ganglion. The precise mechanism of action of metoprolol in migraine prophylaxis is not known, but modification of cortical excitability by inhibiting central $\beta$-receptors most likely contributes to its preventative effects [36-38].

\section{Conclusions}

Pretreatment with MPD blocked IL-1 $\beta-$, but not $\mathrm{PGE}_{2^{-}}$ induced CGRP release in cultured primary trigeminal ganglia cells. Based on our findings, we propose that MPD used for short-term cluster headache prophylaxis or prevention of migraine recurrence might act via the suppression of cytokine mediated trigeminal activation.

\section{Abbreviations}

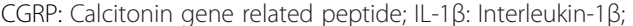

MDP: Methylprednisolone; MTP: Metoprolol; PGE $E_{2}$ : Prostaglandin $E_{2}$.

\section{Competing interests}

The authors declare that they have no competing interests.

\section{Authors' contributions}

LN and UR designed the study. LN, PH and JH performed the experiments and analyzed the data. UR and UD supervised the study. LN wrote the manuscript, and all authors read and approved the final draft of the manuscript.

\section{Acknowledgements}

This work was supported by a grant from the Bundesministerium für Bildung und Forschung (BMBF 01EM 0515). The BMBF had no role in the study design, data collection and analysis, decision to publish, or preparation of the manuscript. We are grateful to Sonja Blumenau for excellent technical assistance.

\section{Author details}

${ }^{1}$ Department of Neurology and Experimental Neurology, Charité Universitätsmedizin Berlin, Charitéplatz 1, 10117 Berlin, Germany. ²Department of Neuroradiology, Universitätsmedizin Göttingen, Robert-Koch-Straße 40, 37075 Göttingen, Germany. ${ }^{3}$ Department of Systems Neuroscience, University Medical Center Hamburg-Eppendorf, Martinistrasse 52, D-20246 Hamburg, Germany.

Received: 28 December 2015 Accepted: 17 February 2016

Published online: 01 March 2016

\section{References}

1. Uddman R, Edvinsson L, Ekman R, Kingman T, McCulloch J (1985) Innervation of the feline cerebral vasculature by nerve fibers containing calcitonin gene-related peptide: trigeminal origin and co-existence with substance P. Neurosci Lett 62(1):131-136

2. Edvinsson L, Hara H, Uddman R (1989) Retrograde tracing of nerve fibers to the rat middle cerebral artery with true blue: colocalization with different peptides. J Cereb Blood Flow Metab 9(2):212-218

3. Goadsby PJ, Edvinsson L (1994) Human in vivo evidence for trigeminovascular activation in cluster headache. Neuropeptide changes and effects of acute attacks therapies. Brain 117(Pt 3):427-434

4. Goadsby PJ, Edvinsson L, Ekman R (1990) Vasoactive peptide release in the extracerebral circulation of humans during migraine headache. Ann Neurol 28(2):183-187. doi:10.1002/ana.410280213

5. Bigal ME, Walter S, Rapoport AM (2013) Calcitonin gene-related peptide (CGRP) and migraine current understanding and state of development. Headache 53(8):1230-1244. doi:10.1111/head.12179

6. Cernuda-Morollon E, Larrosa D, Ramon C, Vega J, Martinez-Camblor P, Pascual J (2013) Interictal increase of CGRP levels in peripheral blood as a biomarker for chronic migraine. Neurology. doi:10.1212 WNL. Ob013e3182a6cb72.

7. Neeb L, Anders L, Euskirchen P, Hoffmann J, Israel H, Reuter U (2015) Corticosteroids alter CGRP and melatonin release in cluster headache episodes. Cephalalgia 35(4):317-326. doi:10.1177/0333102414539057

8. Neeb L, Hellen P, Boehnke C, Hoffmann J, Schuh-Hofer S, Dirnagl U, Reuter U (2011) IL-1 beta stimulates COX-2 dependent PGE synthesis and CGRP release in rat trigeminal ganglia cells. PLoS One 6(3):e17360. doi:10.1371/ journal.pone.0017360

9. Perini F, D'Andrea G, Galloni E, Pignatelli F, Billo G, Alba S, Bussone G, Toso $\checkmark$ (2005) Plasma cytokine levels in migraineurs and controls. Headache 45(7): 926-931. doi:10.1111/j.1526-4610.2005.05135.x 
10. Sarchielli P, Alberti A, Baldi A, Coppola F, Rossi C, Pierguidi L, Floridi A, Calabresi P (2006) Proinflammatory cytokines, adhesion molecules, and lymphocyte integrin expression in the internal jugular blood of migraine patients without aura assessed ictally. Headache 46(2):200-207. doi:10.1111/ j.1526-4610.2006.00337.x

11. Martelletti P, Granata M, Giacovazzo M (1993) Serum interleukin-1 beta is increased in cluster headache. Cephalalgia 13(5):343-345, discussion 307-348

12. Huang $Y$, Cai $X$, Song $X$, Tang H, Huang Y, Xie S, Hu Y (2013) Steroids for preventing recurrence of acute severe migraine headaches: a meta-analysis. Eur J Neurol 20(8):1184-1190. doi:10.1111/ene.12155

13. Durham PL, Russo AF (1999) Regulation of calcitonin gene-related peptide secretion by a serotonergic antimigraine drug. J Neurosci 19(9):3423-3429

14. Durham PL, Niemann C, Cady R (2006) Repression of stimulated calcitonin gene-related peptide secretion by topiramate. Headache 46(8):1291-1295. doi:10.1111/j.1526-4610.2006.00538.x

15. Durham PL, Cady R (2004) Regulation of calcitonin gene-related peptide secretion from trigeminal nerve cells by botulinum toxin type A: implications for migraine therapy. Headache 44(1):35-42. doi:10.1111/j.1526-4610.2004. 04007.x, discussion 42-33

16. Rohatagi S, Barth J, Mollmann H, Hochhaus G, Soldner A, Mollmann C, Derendorf H (1997) Pharmacokinetics of methylprednisolone and prednisolone after single and multiple oral administration. J Clin Pharmacol 37(10):916-925

17. Baylis EM, Williams IA, English J, Marks V, Chakraborty J (1982) High dose intravenous methylprednisolone "pulse" therapy in patients with rheumatoid disease. Plasma methylprednisolone levels and adrenal function. Eur J Clin Pharmacol 21(5):385-388

18. Oosterhuis B, Jonkman JH, Kerkhof FA (1988) Pharmacokinetic and pharmacodynamic comparison of a new controlled-release formulation of metoprolol with a traditional slow-release formulation. Eur J Clin Pharmacol 33(Suppl):S15-18

19. Hoffmann J, Wecker S, Neeb L, Dirnagl U, Reuter U (2012) Primary trigeminal afferents are the main source for stimulus-induced CGRP release into jugular vein blood and CSF. Cephalalgia 32(9):659-667. doi:10.1177/0333102412447701

20. Ho TW, Edvinsson L, Goadsby PJ (2010) CGRP and its receptors provide new insights into migraine pathophysiology. Nat Rev Neurol 6(10):573-582. doi: 10.1038/nrneurol.2010.127

21. Fanciullacci M, Alessandri M, Figini M, Geppetti P, Michelacci S (1995) Increase in plasma calcitonin gene-related peptide from the extracerebral circulation during nitroglycerin-induced cluster headache attack. Pain 60(2):119-123

22. Fanciullacci M, Alessandri M, Sicuteri R, Marabini S (1997) Responsiveness of the trigeminovascular system to nitroglycerine in cluster headache patients. Brain 120(Pt 2):283-288

23. Empl M, Forderreuther S, Schwarz M, Muller N, Straube A (2003) Soluble interleukin-2 receptors increase during the active periods in cluster headache. Headache 43(1):63-68

24. Steinberg A, Sjostrand C, Sominanda A, Fogdell-Hahn A, Remahl Al (2011) Interleukin-2 gene expression in different phases of episodic cluster headache-a pilot study. Acta Neurol Scand 124(2):130-134. doi:10.1111/j. 1600-0404.2010.01434.x

25. Bowen EJ, Schmidt TW, Firm CS, Russo AF, Durham PL (2006) Tumor necrosis factor-alpha stimulation of calcitonin gene-related peptide expression and secretion from rat trigeminal ganglion neurons. J Neurochem 96(1):65-77. doi:10.1111/j.1471-4159.2005.03524.x

26. Miller RJ, Jung $H$, Bhangoo SK, White FA (2009) Cytokine and chemokine regulation of sensory neuron function. Handb Exp Pharmacol 194:417-449. doi:10.1007/978-3-540-79090-7_12

27. White FA, Jung $H$, Miller RJ (2007) Chemokines and the pathophysiology of neuropathic pain. Proc Natl Acad Sci U S A 104(51):20151-20158. doi:10. 1073/pnas.0709250104

28. Uceyler N, Schafers M, Sommer C (2009) Mode of action of cytokines on nociceptive neurons. Exp Brain Res 196(1):67-78. doi:10.1007/s00221-009-1755-Z

29. Boettger MK, Weber K, Grossmann D, Gajda M, Bauer R, Bar KJ, Schulz S, Voss A, Geis C, Brauer R, Schaible HG (2010) Spinal tumor necrosis factor alpha neutralization reduces peripheral inflammation and hyperalgesia and suppresses autonomic responses in experimental arthritis: a role for spinal tumor necrosis factor alpha during induction and maintenance of peripheral inflammation. Arthritis Rheum 62(5):1308-1318. doi:10.1002/art.27380

30. Schafers M, Sommer C, Geis C, Hagenacker T, Vandenabeele P, Sorkin LS (2008) Selective stimulation of either tumor necrosis factor receptor differentially induces pain behavior in vivo and ectopic activity in sensory neurons in vitro. Neuroscience 157(2):414-423. doi:10.1016/j.neuroscience.2008.08.067

31. Zhang XC, Kainz V, Burstein R, Levy D (2011) Tumor necrosis factor-alpha induces sensitization of meningeal nociceptors mediated via local COX and p38 MAP kinase actions. Pain 152(1):140-149. doi:10.1016/j.pain.2010.10.002

32. Yan J, Melemedjian OK, Price TJ, Dussor G (2012) Sensitization of dural afferents underlies migraine-related behavior following meningeal application of interleukin-6 (IL-6). Mol Pain 8:6. doi:10.1186/1744-8069-8-6

33. Thalakoti S, Patil W, Damodaram S, Vause CV, Langford LE, Freeman SE, Durham PL (2007) Neuron-glia signaling in trigeminal ganglion: implications for migraine pathology. Headache 47(7):1008-1023. doi:10.1111/j.1526-4610. 2007.00854.x, discussion 1024-1005

34. Mathew NT (2011) Pathophysiology of chronic migraine and mode of action of preventive medications. Headache 51(Suppl 2):84-92. doi:10.1111/ j.1526-4610.2011.01955.x

35. Santini G, Patrignani P, Sciulli MG, Seta F, Tacconelli S, Panara MR, Ricciotti E, Capone ML, Patrono C (2001) The human pharmacology of monocyte cyclooxygenase 2 inhibition by cortisol and synthetic glucocorticoids. Clin Pharmacol Ther 70(5):475-483

36. Gerwig M, Niehaus L, Stude P, Katsarava Z, Diener HC (2012) Beta-blocker migraine prophylaxis affects the excitability of the visual cortex as revealed by transcranial magnetic stimulation. J Headache Pain 13(1):83-89. doi:10.1007/s10194-011-0401-x

37. Maertens de Noordhout A, Timsit-Berthier M, Timsit M, Schoenen J (1987) Effects of beta blockade on contingent negative variation in migraine. Ann Neurol 21(1):111-112. doi:10.1002/ana.410210125

38. Diener HC, Scholz E, Dichgans J, Gerber WD, Jack A, Bille A, Niederberger U (1989) Central effects of drugs used in migraine prophylaxis evaluated by visual evoked potentials. Ann Neurol 25(2):125-130. doi:10.1002/ana.410250204

\section{Submit your manuscript to a SpringerOpen ${ }^{\circ}$ journal and benefit from:}

- Convenient online submission

- Rigorous peer review

- Immediate publication on acceptance

- Open access: articles freely available online

- High visibility within the field

- Retaining the copyright to your article

Submit your next manuscript at $>$ springeropen.com 